\title{
Genetic Diversity in Napier Grass (Pennisetum purpureum) Assessed by SSR Markers
}

\author{
Geofrey Kawube ${ }^{1,2}$, Titus Alicai ${ }^{2}$, Bramwel Wanjala ${ }^{3}$, Moses Njahira ${ }^{4}$, Juma Awalla ${ }^{3}$ \& Robert Skilton ${ }^{4}$ \\ ${ }^{1}$ Faculty of Agriculture and Environment, Gulu University, Gulu, Uganda \\ ${ }^{2}$ National Crops Resources Research Institute, Kampala, Uganda \\ ${ }^{3}$ Biotechnology and Biodiversity, Kenya Agricultural Research Institute, Nairobi, Kenya \\ ${ }^{4}$ Biosciences eastern and central Africa (BecA), International Livestock Research Institute (ILRI) Hub, Nairobi, \\ Kenya \\ Correspondence: Geofrey Kawube, Faculty of Agriculture and Environment, Gulu University, P.O. Box 166 \\ Gulu, Uganda. E-mail: kawgeoff@gmail.com
}

Received: February 10, 2015 Accepted: April 30, 2015 Online Published: June 15, 2015

doi:10.5539/jas.v7n7p147 URL: http://dx.doi.org/10.5539/jas.v7n7p147

\begin{abstract}
Understanding of genetic diversity among Napier grass is very important for selection and improvement of Napier grass breeding population. This study determined the genetic diversity among the farmer preferred, wild (local) and selected ILRI gene-bank Napier grass clones using 23 SSR markers selected from pearl millet, maize and sorghum. The results indicated polymorphism among the SSR markers, revealing a total of 339 alleles of which $27.1 \%$ alleles were unique, occurring either only in local, farmers preferred or ILRI clones. Similarly, genetic diversity and observed heterozygosity were highest in the local than in farmers' preferred and least in the ILRI gene-bank clones. The clones clustered in two groups with a few overlaps, although most of the farmer's grown Napier grass clones grouped with those from ILRI genebank and clone P99, emphasizing their genetic relatedness. Therefore, the unique alleles revealed in the local clones may be associated with adaptability to local environments. These alleles could, therefore, be exploited for genetic improvement of the farmer preferred Napier grass.
\end{abstract}

Keywords: livestock, fodder, gene-bank, genetic improvement, ILRI, Uganda

\section{Introduction}

Napier grass (Pennisetum purpureum Schum) is the main fodder supporting livestock systems in East Africa and constitutes up to $80 \%$ of forage for smallholder dairy farms (Staal et al., 1997). It is a preferred fodder because of its high biomass production, withstands repeated cutting/harvesting, exhibits rapid regeneration and palatability to cattle in its leafy stage (Lowe et al., 2003). Nutritionally, Napier grass contains $4-15 \%$ crude protein, $28-40 \%$ crude fibre, $10-16 \%$ ash, $0.9-3.8 \%$ fat and 39-49\% nitrogen free extract (Skerman \& Riveros, 1990). Besides, this grass has the potential to produce biofuels, such as charcoal, alcohol and methane (Anderson et al., 2008; Strezov et al., 2008; Jakob et al., 2009; Morais et al., 2009; Lee et al., 2010). In China, the grass is also used as forage and raw material for paper industry and sometimes as culture substrate for mushroom (Zhou et al., 2007).

Napier grass has received little research attention compared to other cereal crops, despite its importance to the livestock industry. Currently, the productivity of Napier grass is limited by several factors especially emerging diseases including Napier grass stunt disease and Napier grass head smut disease (Kawube et al., 2014; New Agriculturalist, 2009) which remedy could be found through crop improvement. However, the Ugandan Napier grass germplasm has not been fully characterized and consists of two types; the non-flowering which is widely grown and exchanged among farmers without pedigree records and the flowering type - which mainly grows freely in the wild habitats. Besides, the international Livestock Resources Research Institute in Ethiopia maintains a collection of Pennisetum purpureum and its hybrids (Pennisetum glaucum), collected from several African countries and USA (Van de Wouw et al., 1999); and this offers the most dependable Napier grass germplasm source (Kawube et al., 2014). Therefore, there is need for proper identification of Napier grass accessions as a prerequisite for improvement of the crop to ensure the right clone is chosen (Xie et al., 2009). 
Elsewhere, Napier grass characterization has largely depended on morphological (Bhandari et al., 2004) and agronomic features and is the major cause of inconsistency in Napier grass identification (Wanjala et al., 2013). Other tools including use of DNA fingerprinting techniques that can be applied quickly and easily are available (Weising et al., 1995). Of these, simple sequence repeat (SSR) markers are of choice because they detect variation in allele frequency at many unlinked loci, are abundant in the plant genome, have high level of polymorphism and are adaptable to automation (Donini et al., 1998). However, their utilization requires prior knowledge of genome sequence of an organism to facilitate design of appropriate primers. The genome of Napier grass is not yet sequenced, as such, a viable alternative is to use cross-amplification between closely related species (Azevedo et al., 2012). This study, therefore, was carried out to determine genetic diversity within and among farmer-preferred Napier grass in Uganda in comparison with some of the collections from ILRI (Ethiopia) germplasm bank using selected pearl millet, sorghum and maize SSR markers.

\section{Materials and Methods}

\subsection{Sample Collection}

Actively growing young unfolded Napier grass leaf samples were collected from wild habitats and farmers' fields, in two districts in each of the four selected regions of Uganda - northern, western, central and eastern. In each region, 13 and 24 wild type/local and farmers' preferred/improved Napier grass leaf samples, respectively were collected from locations with a minimum distance of 3 kilometers apart. The samples were put in a polythene bag and immediately put on dry ice in cold box and transported to National Crops Resources Research Institute (NaCRRI) laboratory. In addition, one leaf sample from each of the known farmers preferred Napier grass clones (P99 and KW4), wild type/local and clones 16785, 16792, 16795, 16803, 16806, 16814 and 16837, imported from ILRI gene bank (Ethiopia) and planted in a screen house at NaCRRI were collected two months after planting as described above. This made a total collection of 159 samples. The samples were transported to Biosciences Eastern and Central Africa (BecA) laboratory in Nairobi-Kenya for analysis on dry ice.

\subsection{DNA Extraction}

In the laboratory, $1.5 \mathrm{~g}$ from each of the 159 Napier grass leaf samples were ground in a mortar in liquid nitrogen. Total plant DNA was extracted from the crushed samples using cetyl-trimethyl-ammonium bromide (CTAB) method (J. Doyle \& J. Doyle, 1990). The DNA was diluted in $100 \mu$ of double distilled water, kept at $4{ }^{\circ} \mathrm{C}$ for 24 hours to allow it dissolve completely. To remove RNA from the samples, a volume of $3 \mu l$ of RNAse $(10 \mathrm{mg} / \mathrm{ml})$ was added to the DNA sample and incubated at $37{ }^{\circ} \mathrm{C}$ for one hour and washed using $70 \%$ ethanol. The concentration of the DNA was determined using Nanodrop UV spectrometry at A260 and A280 while its integrity was tested on $1.2 \%$ agarose gel electrophoresis in TBE buffer stained with gel red. Template DNA was made by diluting the DNA to $25 \mathrm{ng} / \mu$.

\subsection{DNA Amplification with Microsatellite Markers and Capillary Electrophoresis}

A total of 23 simple sequence repeat microsatellite primer pairs, originally identified in maize, pearl millet, rice and sorghum were conjugated with different dyes (VIC, NED, PET and 6-FAM). These were used to PCR amplification of Napier grass in $20 \mu \mathrm{l}$ reaction mixture containing AccuPower ${ }^{\circledR}$ Taq Premix (Bioneer) to which $17 \mu \mathrm{l}$ of water and $0.5 \mu \mathrm{l}$ (of 5 picomoles of each of the primer pair) and $2 \mu \mathrm{l}$ of template DNA were added. The conditions used were: an initial denaturation of $94{ }^{\circ} \mathrm{C}(3 \mathrm{~min})$ followed by 35 cycles of $94{ }^{\circ} \mathrm{C}(30 \mathrm{sec})$; specific primer annealing temperature $(1 \mathrm{~min})$ (Table 1); extension at $72{ }^{\circ} \mathrm{C}(2 \mathrm{~min})$, final extension at $72{ }^{\circ} \mathrm{C}(10 \mathrm{~min})$ and final hold at $4{ }^{\circ} \mathrm{C}$. The PCR products were run on $1.2 \%$ agarose gel electrophoresis stained with gel red in $0.5 \mathrm{X}$ TBE buffer at $80 \mathrm{~V}$ for 50 minutes and visualized on trans UV and photographed in UVP DIGIDOC - IT system (UVP Bioimaging systems, USA). PCR products with clear single band amplification on the agarose gel were each added to HIDI formamide with A LIZ-500 size standard and subjected to capillary electrophoresis with ABI3730 DNA genetic analyser for fragment analysis. Allele calls were made using GENEMAPPER software v.3.7 (Applied Biosystems). 
Table 1. SSR markers used to assess genetic diversity in 159 Napier grass accessions

\begin{tabular}{|c|c|c|c|}
\hline Primer & Sequence Left primer (Forward 5' $-3^{\prime}$ ) & Right primer (reverse 5' - 3') & $\begin{array}{l}\text { Annealing } \\
\text { temperature }\left({ }^{\circ} \mathrm{C}\right)\end{array}$ \\
\hline CTM-10 & GAGGCAAAAGTGGAAGACAG & TTGATTCCCGGTTCTATCGA & 52 \\
\hline CTM-12 & GTTGCAAGCAGGAGTAGATCGA & CGCTCTGTAGGTTGAACTCCTT & 52 \\
\hline CTM-27 & GTTGCAAGCAGGAGTAGATCGA & CGCTCTGTAGGTTGAACTCCTT & 52 \\
\hline CTM-59 & TCCTCGACATCCTCCA & GACACCTCGTAGCACTCC & 54 \\
\hline CTM-8 & GCTGCATCGGAGATAGGGAA & CTCAGCAAGCACGCTGCTCT & 52 \\
\hline PGIRD13 & CAGCAGCGAGAAGTTTAGCA & GCGTAGACGGCGTAGATGAT & 60 \\
\hline PGIRD21 & GCTATTGCCACTGCTTCACA & CCACCATGCAACAGCAATAA & 54 \\
\hline PGIRD25 & CGGAGCTCCTATCATTCCAA & GCAAGCCACAAGCCTATCTC & 58 \\
\hline PGIRD5 & CAACCCAACCCATTATACTTATCTG & GCAACTCTTGCCTTTCTTGG & 58 \\
\hline PGIRD56 & ATCACTCCTCGATCGGTCAC & ACCAGACACACGTGCCAGT & 58 \\
\hline PGIRD57 & GGCCCCAAGTAACTTCCCTA & TCAAGCTAGGGCCAATGTCT & 56 \\
\hline PSMP2235 & GCTTTTCTGCTTCTCCGTAGAC & CCCAACAATAGCCACCAATAAAGA & 54 \\
\hline PSMP2248 & TCTGTTTGTTTGGGTCAGGTCCTTC & CGAATACGTATGGAGAACTGCGCATC & 58 \\
\hline PSMP2255 & CATCTAAACACAACCAATCTTGAAC & TGGCACTCTTAAATTGACGCAT & 54 \\
\hline PSMP2266 & CAAGGATGGCTGAAGGGCTATG & TTTCCAGCCCACACCAGTAATC & 58 \\
\hline PSMP2267 & GGAAGGCGTAGGGATCAATCTCAC & ATCCACCCGACGAAGGAAACGA & 60 \\
\hline Xipes0093 & GGATCTGCAGGTTTGGACAT & CCAAGCACTGAAACATGCAC & 57 \\
\hline Xipes0191 & GAAGAACCTCCAGCTTTCCC & TTCTTTCCTTCAGCCTCTGC & 53 \\
\hline Xipes0219 & GGGGAAGAGATAGGGTTGGT & AGCTGGGCAATAGCGAGAT & 57 \\
\hline Phil227562 & TGATAAAGCTCAGCCACAAGG & ATCTCGGCTACGGCCAGA & 56 \\
\hline Xcup14 & TACATCACAGCAGGGACAGG & CTGGAAAGCCGAGCAGTATG & 53 \\
\hline Xcup63 & GTAAAGGGCAAGGCAACAAG & GCCCTACAAAATCTGCAAGC & 53 \\
\hline XTXP278 & GGGTTTCAACTCTAGCCTACCGAACTTCCT & ATGCCTCATCATGGTTCGTTTTGCTT & 50 \\
\hline
\end{tabular}

\subsection{Data Analysis}

Data generated by GENEMAPPER software v.3.7 (Applied Biosystems) was transferred to excel and analyzed for various genetic parameters which included number of alleles per locus, heterozygosity (Ho), gene diversity $(\mathrm{He})$, polymorphic information content (PIC), genetic differentiation index (Fst) and fixation index (f) using Powermarker software (Liu \& Muse, 2005) and GenalEX (Peakall \& Smouse, 2006). Similarity between the different Napier grass samples was analyzed using Principal co-ordinate Analysis (PCoA) by GenALEx (Peakall \& Smouse, 2006) and a dendrogram based on UPGMA was generated using Darwin software (Perrier \& Jacquemound-Collet, 2006) with 1000 bootstrap replicates.

\section{Results}

\subsection{Characteristics of SSR Markers}

Genetic diversity parameters assessed by the 23 SSR markers across all the Napier grass populations are presented in Table 2. All SSR markers were polymorphic, generating a total of 339 polymorphic alleles, ranging from 4 to 37, with an average of 14.74 alleles. Primer Phill227562 recorded the highest number (37) of alleles, followed by CTM8 (30), while the least number (4) was recorded with primer Xcup14. In relation, polymorphic information content of all loci across all Napier clones was also high, ranging from 0.51 (CTM59) to 0.94 (Phill227562) with an average of 0.69. The genetic differentiation among the Napier grass clones as revealed by the 23 SSR markers as averaged over all loci, was low (mean $=0.07$ ), ranging from 0.01 (XTXP278) to 0.2 (PSMP2248). Inbreeding coefficient across the Napier grass clones was negative (mean $=-0.03$ ), ranging from 0.07 (Phil 227562) to 0.83 (Xipes0191) (Table 2). 
Table 2. Genetic diversity parameters averaged across all groups and loci for 66 genotypes

\begin{tabular}{|c|c|c|c|c|c|c|c|}
\hline Markers & $\begin{array}{l}\text { Major Allele } \\
\text { Frequency }\end{array}$ & Allele No & $\begin{array}{l}\text { Observed } \\
\text { Heterozygosity (Ho) }\end{array}$ & $\begin{array}{l}\text { Heterozygosity } \\
(\mathrm{He})\end{array}$ & Fixation Index & PIC & Fst \\
\hline CTM10 & 0.46 & 11 & 0.67 & 0.61 & -0.13 & 0.73 & 0.08 \\
\hline CTM59 & 0.65 & 9 & 0.38 & 0.36 & -0.08 & 0.51 & 0.04 \\
\hline CTM8 & 0.23 & 30 & 0.9 & 0.85 & -0.07 & 0.88 & 0.04 \\
\hline CTM12 & 0.54 & 9 & 0.69 & 0.52 & -0.32 & 0.57 & 0.08 \\
\hline CTM27 & 0.53 & 8 & 0.77 & 0.53 & -0.47 & 0.6 & 0.03 \\
\hline PGIRD13 & 0.43 & 29 & 0.76 & 0.87 & 0.13 & 0.79 & 0.03 \\
\hline PGIRD21 & 0.28 & 27 & 0.77 & 0.79 & 0.01 & 0.89 & 0.06 \\
\hline PGIRD57 & 0.5 & 11 & 0.31 & 0.56 & 0.47 & 0.68 & 0.07 \\
\hline PSMP2248 & 0.5 & 10 & 0.1 & 0.39 & 0.76 & 0.62 & 0.2 \\
\hline Xipes0093 & 0.48 & 6 & 0.94 & 0.75 & -0.26 & 0.65 & 0.03 \\
\hline Phil227562 & 0.16 & 37 & 0.96 & 0.56 & -0.71 & 0.94 & 0.03 \\
\hline Xcup14 & 0.42 & 4 & 0.53 & 0.5 & -0.06 & 0.61 & 0.15 \\
\hline PSMP2266 & 0.64 & 8 & 0.97 & 0.63 & -0.58 & 0.52 & 0.06 \\
\hline PGIRD5 & 0.63 & 7 & 0.07 & 0.29 & 0.69 & 0.54 & 0.14 \\
\hline PSMP2235 & 0.47 & 8 & 0.79 & 0.57 & -0.44 & 0.65 & 0.02 \\
\hline PGIRD25 & 0.61 & 11 & 0.21 & 0.27 & 0.25 & 0.57 & 0.08 \\
\hline PSMP2267 & 0.21 & 24 & 0.82 & 0.78 & -0.05 & 0.89 & 0.04 \\
\hline PSMP2255 & 0.49 & 19 & 0.68 & 0.77 & 0.11 & 0.71 & 0.09 \\
\hline Xipes0191 & 0.29 & 17 & 0.12 & 0.69 & 0.83 & 0.79 & 0.07 \\
\hline XTXP278 & 0.58 & 8 & 0.83 & 0.57 & -0.46 & 0.57 & 0.01 \\
\hline Xcup63 & 0.42 & 11 & 0.97 & 0.67 & -0.46 & 0.62 & 0.02 \\
\hline PGIRD56 & 0.24 & 18 & 0.71 & 0.69 & -0.02 & 0.85 & 0.04 \\
\hline Xipes0219 & 0.31 & 17 & 0.49 & 0.68 & 0.27 & 0.83 & 0.09 \\
\hline Mean & 0.44 & 14.74 & 0.63 & 0.60 & -0.03 & 0.69 & 0.07 \\
\hline
\end{tabular}

The expected hetereozygosity (gene diversity) across all populations was high, ranging from 0.55 (PSMP2266) to 0.90 (PGIRD21) with an average of 0.60 . Similarly, observed heterozygosity was high ranging from 0.10 (PSMP2248) to 0.97 (PSMP2266) with an average of 0.63. The expected hetereozygosity was the highest in the local germplasm (0.69), followed by improved (0.61) and the least in ILRI genebank populations (0.51) (Table $3)$. The highest number of alleles were recorded in the local, followed by the improved, and the least in the Ethiopia germplasm Table 3). Of the 339 alleles identified by the markers, $92(27.1 \%)$ were unique occurring in the Ethiopian, improved and local clones at 4 (4.2\%), 35 (36.5.0\%) and 57 (59.4\%), respectively, with most of them occurring at very low $(<0.05)$ frequencies in the population (Table 4$)$.

Table 3. Genetic diversity indices, population, number of different alleles $(\mathrm{Na})$, number of effective alleles (Ne), Shanon information index (I) and unbiased expected heterozygosity $(\mathrm{He})$ and polymorphic loci and \% polymorphic loci

\begin{tabular}{llll}
\hline Population & Ethiopia & improved & local \\
\hline $\mathrm{Na}$ & 3.217 & 7.435 & 8.217 \\
$\mathrm{Ne}$ & 2.636 & 3.260 & 3.994 \\
$\mathrm{I}$ & 0.905 & 1.291 & 1.533 \\
No. Private Alleles & 0.174 & 1.522 & 2.304 \\
$\mathrm{He}$ & 0.508 & 0.611 & 0.694 \\
\% polymorphism & 86.9 & 100 & 100 \\
\hline
\end{tabular}


Table 4. Allele frequencies of unique alleles by population in Uganda and ILRI germplasm

\begin{tabular}{|c|c|c|c|c|c|c|c|c|}
\hline \multicolumn{3}{|c|}{ Local/wild type } & \multicolumn{3}{|c|}{ Improved } & \multicolumn{3}{|c|}{ Ethiopia } \\
\hline Locus & Allele & Frequency & Locus & Allele & Frequency & Locus & Allele & Frequency \\
\hline CTM10 & 212 & 0.01 & CTM10 & 127 & 0.022 & CTM8 & 243 & 0.167 \\
\hline CTM59 & 165 & 0.069 & CTM10 & 189 & 0.028 & СТM8 & 267 & 0.083 \\
\hline CTM8 & 126 & 0.033 & CTM59 & 157 & 0.015 & Xipes0191 & 135 & 0.25 \\
\hline CTM8 & 134 & 0.011 & CTM8 & 265 & 0.038 & XTXP278 & 91 & 0.071 \\
\hline CTM8 & 199 & 0.033 & CTM12 & 284 & 0.037 & & & \\
\hline CTM8 & 222 & 0.011 & CTM13 & 188 & 0.04 & & & \\
\hline CTM8 & 238 & 0.022 & CTM13 & 199 & 0.03 & & & \\
\hline CTM8 & 261 & 0.033 & CTM13 & 222 & 0.02 & & & \\
\hline CTM12 & 300 & 0.037 & CTM13 & 241 & 0.03 & & & \\
\hline CTM12 & 309 & 0.056 & PGIRD21 & 200 & 0.092 & & & \\
\hline СТM27 & 250 & 0.011 & PGIRD21 & 214 & 0.02 & & & \\
\hline СТM27 & 295 & 0.033 & PSMP2248 & 142 & 0.011 & & & \\
\hline CTM27 & 299 & 0.011 & Xipes0093 & 120 & 0.019 & & & \\
\hline СТM27 & 308 & 0.022 & Xipes0093 & 136 & 0.026 & & & \\
\hline PGIRD13 & 139 & 0.015 & PGIRD5 & 158 & 0.054 & & & \\
\hline PGIRD13 & 155 & 0.015 & PGIRD25 & 200 & 0.011 & & & \\
\hline PGIRD13 & 160 & 0.015 & PSMP 2267 & 197 & 0.017 & & & \\
\hline PGIRD13 & 209 & 0.015 & PSMP 2267 & 200 & 0.029 & & & \\
\hline PGIRD13 & 225 & 0.044 & PSMP 2267 & 228 & 0.029 & & & \\
\hline PGIRD13 & 259 & 0.044 & PSMP 2255 & 83 & 0.074 & & & \\
\hline PGIRD13 & 265 & 0.015 & PSMP 2255 & 115 & 0.021 & & & \\
\hline PGIRD13 & 269 & 0.044 & Xipes0191 & 73 & 0.041 & & & \\
\hline PGIRD21 & 236 & 0.016 & Xipes0191 & 75 & 0.007 & & & \\
\hline PGIRD21 & 241 & 0.016 & Xipes0191 & 81 & 0.014 & & & \\
\hline PGIRD21 & 259 & 0.109 & Xipes0191 & 150 & 0.027 & & & \\
\hline PGIRD21 & 265 & 0.031 & XTXP278 & 101 & 0.026 & & & \\
\hline PGIRD21 & 268 & 0.047 & Xcup63 & 162 & 0.01 & & & \\
\hline PGIRD57 & 89 & 0.038 & PGIRD56 & 114 & 0.017 & & & \\
\hline PSMP2248 & 158 & 0.044 & PGIRD56 & 134 & 0.022 & & & \\
\hline PSMP2248 & 161 & 0.122 & PGIRD56 & 140 & 0.006 & & & \\
\hline Xipes0093 & 114 & 0.032 & PGIRD56 & 141 & 0.011 & & & \\
\hline Xipes0093 & 118 & 0.021 & PGIRD56 & 187 & 0.022 & & & \\
\hline Xipes0093 & 143 & 0.011 & Xipes0219 & 140 & 0.008 & & & \\
\hline PSMP2266 & 162 & 0.025 & Xipes0219 & 148 & 0.091 & & & \\
\hline PSMP2266 & 171 & 0.075 & Xipes0219 & 152 & 0.03 & & & \\
\hline PGIRD5 & 148 & 0.04 & & & & & & \\
\hline PSMP2235 & 214 & 0.042 & & & & & & \\
\hline PSMP2235 & 221 & 0.083 & & & & & & \\
\hline PSMP2235 & 226 & 0.042 & & & & & & \\
\hline PSMP2235 & 241 & 0.028 & & & & & & \\
\hline PSMP2235 & 259 & 0.042 & & & & & & \\
\hline PSMP2235 & 269 & 0.042 & & & & & & \\
\hline PGIRD25 & 175 & 0.056 & & & & & & \\
\hline PGIRD25 & 190 & 0.022 & & & & & & \\
\hline PGIRD25 & 236 & 0.1 & & & & & & \\
\hline PGIRD25 & 258 & 0.033 & & & & & & \\
\hline PSMP 2267 & 212 & 0.021 & & & & & & \\
\hline PSMP 2255 & 87 & 0.065 & & & & & & \\
\hline PSMP 2255 & 91 & 0.065 & & & & & & \\
\hline PSMP 2255 & 120 & 0.016 & & & & & & \\
\hline PSMP 2255 & 218 & 0.016 & & & & & & \\
\hline Xcup63 & 51 & 0.02 & & & & & & \\
\hline Xcup63 & 131 & 0.039 & & & & & & \\
\hline Total & 57 & & & & 35 & & & 4 \\
\hline
\end{tabular}




\subsection{Genetic Relationships}

Principle coordinate analysis (PCoA) delineated the clones into two population structures, each with an overlap of farmer preferred and local Napier grass samples. There are also farmer preferred and local clones which are not grouped into any definitive structure but widely dispersed (Figure 1). Similar grouping was achieved with the dendrogram, and the ILRI germplasm grouped together with P99 and wild type. Clone KW4 did not group with any Napier grass clone from ILRI genebank, but with some farmer preferred/improved clones (Figure 2).

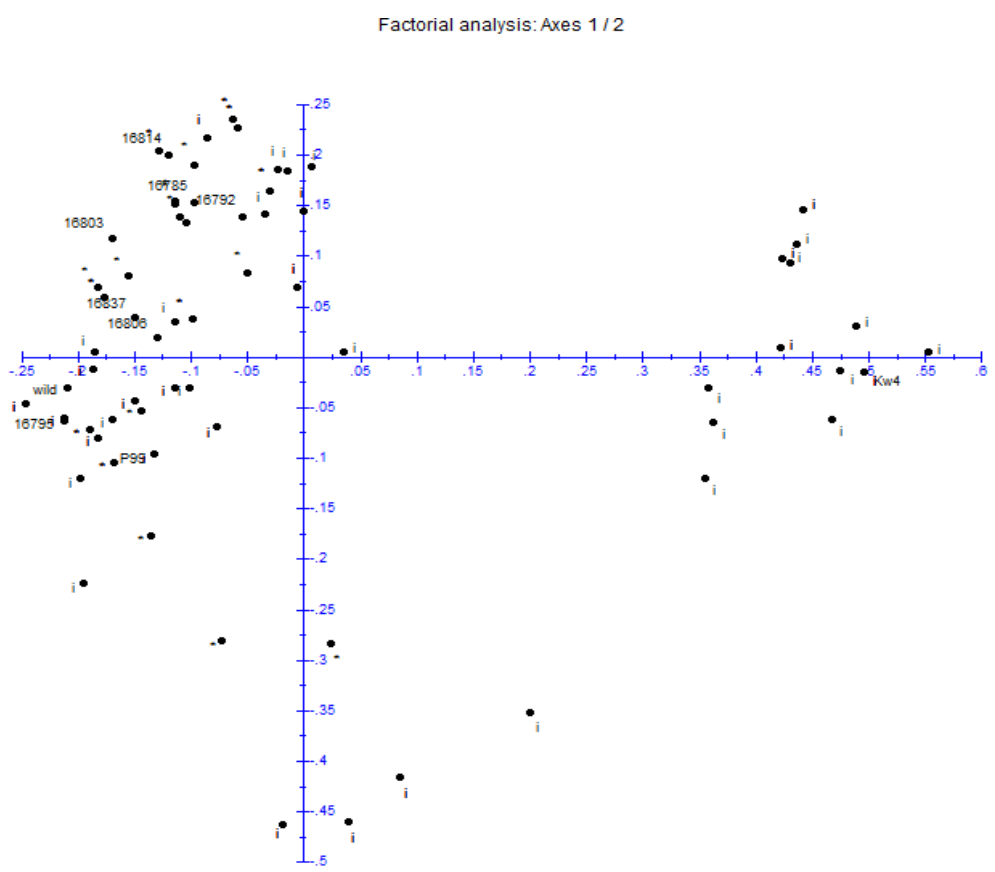

Figure 1. Biplot of principle coordinate analysis based on the dissimilarity of Napier grass. Sample numbers with prefix i and * are improved/farmer preferred and local clones, respectively. Sample numbers without prefix were obtained from ILRI germplasm Bank

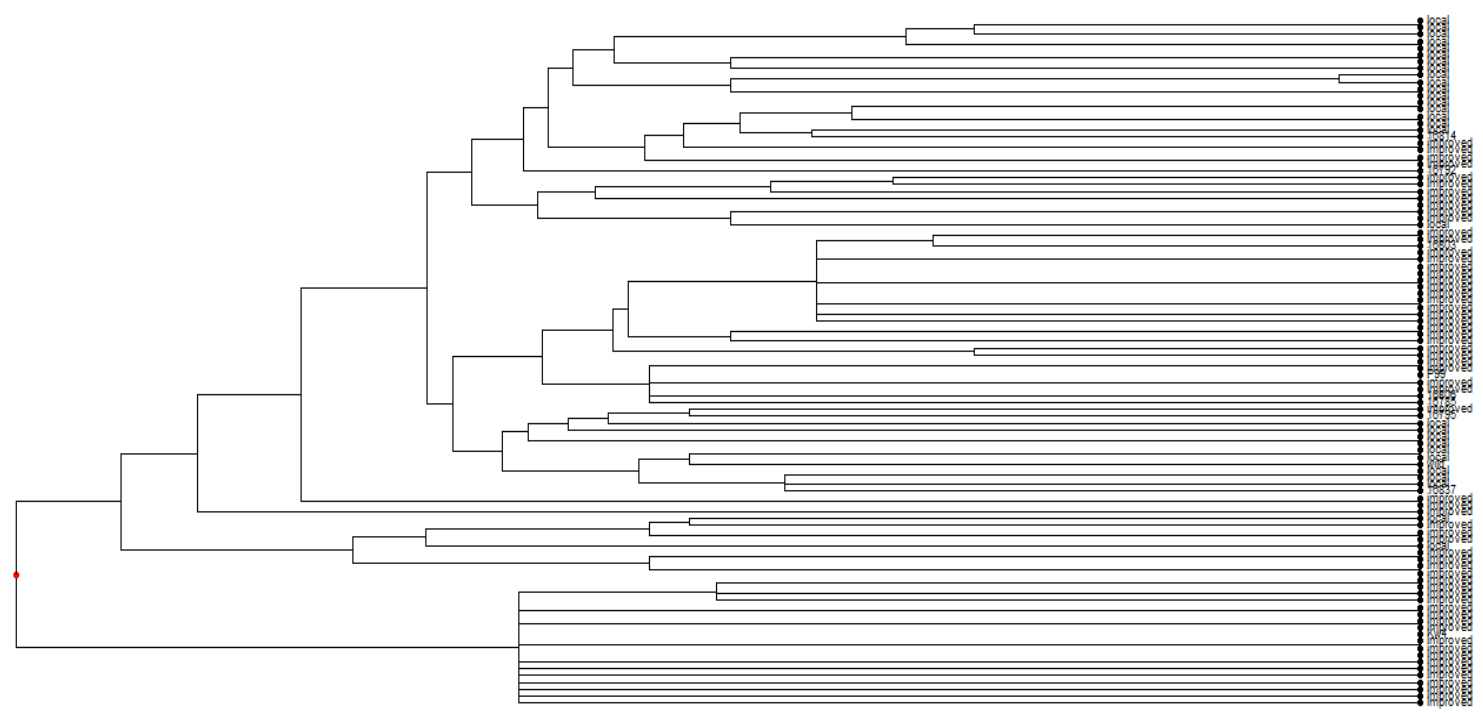

Figure 2. Dendrogram showing relationships among Napier grass clones 


\section{Discussion}

Genotyping of Napier grass clones was achieved using 23 SSR markers on 159 samples. All markers used in this study produced high mean PIC indicating their ability to discriminate among and within individuals in population. However, PIC values varied from one marker to another due to influence of markers and clones used in the study (Elibariki et al., 2013). In relation, the mean number of alleles per locus was higher than what was previously reported (Azevedo et al., 2012), implying that the loci targeted by SSR markers in this study are highly informative.

Genetic diversity among breeding materials is essential for plant breeders in choosing parents and maintaining genetic diversity within a population. High expected and observed heterozygosity in the Napier grass revealed in this study implies a rich population of Napier grass which can be exploited in breeding strategies. The highest genetic diversity was observed among local grass, a factor attributed to spontaneous recombination as a result of out-crossing among themselves (Azavedo et al., 2012). Compared to the ILRI Napier grass clones, farmers preferred Napier grass clones revealed a relatively high genetic diversity which could be due to introductions from elsewhere into the country which is often unregistered, thus hampering their proper utilization. This result is similar to earlier findings by Wanjala et al. (2013) who reported high genetic diversity among Ugandan Napier clones using AFLP markers. The low genetic diversity in the ILRI genebank clone is due to sharing of most of the alleles within themselves, thus reducing the genetic base.

The genetic differentiation and inbreeding coefficient across all loci was low and negative, implying that there is some random mating in some of the Napier clones, especially the local Napier grass clones since it is open pollinated and as such, gene flow among clones is high and most genetic variation resides between rather than within cultivars (Xie et al., 2009). This also explains the highest number of private alleles in the local than in the farmer preferred and ILRI clones. The private alleles need to be exploited in breeding programs to broaden or widen genetic base and increase the chances of producing clones with farmer preferred traits. The relatively high number of unique alleles in farmers preferred clones in Uganda may be explained by introduction of clones with unique alleles from elsewhere and due to mutation. However, the low number of unique alleles in ILRI clones may be attributed to fact that most of these clones were sampled from the rest of Africa and probably share most of the alleles with those in Uganda.

The dendrogram reveals the distance between distinct materials which assists plant breeders in making choices for the breeding program (Xie et al., 2009). In this study, the clustering of the clones by both PcoA and dendrogram revealed two major groups with several subdivisions, duplicates and overlaps. However, the clustering did not fully discriminate the local, farmer preferred and ILRI clones, indicating a high likelihood that alleles are shared between the different clones. The Capacity of the SSR markers to discriminate among the clones was revealed by the dendrogram, grouping the three known Ugandan clones (P99, KW4 and local) differently. The genetic distance between these three clones was further elucidated by PCA which showed stronger association between clone P99 and local than with clone KW4. Furthermore, the clustering showed that most of the clones grown by farmers are closely related to clone P99 and ILRI clones than KW4.

\section{Conclusion}

This study has revealed high genetic diversity among the Napier grass with the wild/local population having most unique alleles than farmers preferred/improved and the ILRI gene-bank populations. The unique alleles may be associated with traits such as resistance to diseases, high yield among others which are preferred by farmers. These ought to be exploited by breeding programs in tackling Napier grass production challenges. The high level of genetic diversity in the wild/local and farmer preferred clone populations highlights the need for establishment of the Genebank with well characterized Napier grass clones to facilitate their utilisation. The variable levels of genetic differentiation between and within the different populations provide an opportunity for selection of diverse parents to be used in parental crosses.

\section{Reference}

Anderson, W. F., Dien, B. S., Brandon, S. K., \& Peterson, J. D. (2008). Assessment of Bermuda grass and bunch grasses as feed stocks for conversion to ethanol. Applied Biochemistry and Biotechnology, 145, 13-21. http://dx.doi.org/10.1007/s12010-007-8041-y

Azevedo, A. L. S., Costa, P. P., Machado, J. C., Machando, M. A., Pereira, A. V., \& Ledo, F. J. S. (2012). Cross species amplification of Pennisetum glaucum microsatellite markers in Pennisetum purpureum and genetic diversity of Napier grass accessions. Crop Science, 4, 1776-1785. http://dx.doi.org/10.2135/cropsci2011.09.0480 
Bhandari, A. P., Sukanya, D. H., \& Ramesh, C. R. (2006). Application of isozyme data in fingerprinting napiergrass (Pennisetum purpureum Schum.) for germplasm management. Genetic. Resources. Crop Evolution, 53, 253-264. http://doi:10.1007/s10722- 004-6120-2

Donini, P., Stephenson, P., Bryan, G. J., \& Koebner, R. M. D. (1998). The potential of microsatellites for high throughput diversity assessment in wheat and barley. Genetic Resources and Crop Evolution, 45, 415-421. http://dx.doi.org/10.1023/A:1008612917967

Doyle, J., \& Doyle, J. (1990). Isolation of plant DNA from fresh tissue. Focus, 12, 13-15.

Elibariki, G., Njahira, M., Wanjala, B., Hosea, K., \& Ndunguru, J. (2013). Genetic diversity and identification of duplicates in selected Tanzanian farmer preferred cassava landraces using simple sequence repeat (SSR) markers. International Journal of Research in Plant Science, 3(4), 81-87.

Jakob, K., Zhou, F., \& Paterson, A. H. (2009). Genetic improvement of C4 grasses as cellulosic biofuel feed stocks. In Vitro Cellular \& Developmental Biology. Plant, 45, 291-305. http://dx.doi.org/10.1007/s11627-009-9214-x

Kawube, G., Alicai, T., Otim, O., Mukwaya, A., Kabirizi, J., \& Talwana, H. (2014). Resistance of Napier grass clones to Napier grass stunt disease. African Crop Science Journal, 22(3), 109-115

Lee, M. K., Tsai, W. T., Tsai, Y. L., \& Lin, S. H. (2010). Pyrolysis of Napier grass in an induction-heating reactor. Journal of Analystical and Applied pyrolysis, 88, 110-116. http://dx.doi.org/10.1016/j.jaap.2010.03.003

Liu, K., \& Muse, S. V. (2005). PowerMarker: Integrated analysis environment for genetic marker data. Bioinformatics, 21(9), 2128-2129. http://dx.doi.org/10.1093/bioinformatics/bti282

Lowe, A. J., Thorpe, W., Teale, A., \& Hanson, J. (2003). Characterisation of germplasm accessions of Napier grass (Pennisetum purpureum and Pennisetum purpureum $\times$ Purpureum glaucum Hybrids) and comparison with farm clones using RADP. Genetic resources and Crop Evolution, 50, 121-132. http://dx.doi.org/10.1023/A:1022915009380

Morais, R. F., Souza, B. J., Leite, J. M., Soares, L. H. B., Alves, B. J. R., Boddy, R. M., \& Urquiaga, S. (2009). Elephant grass genotypes for bioenergy production by direct biomass combustion. Pesquisa Agropecuária Brasileira, 44, 133-140. http://dx.doi.org/10.1590/S0100-204X2009000200004

New Agriculturists. (2009). A healthy aversion to smut. Retrieved November 1, 2009, from http://www.new-ag.info/98-2/newsbr.html

Peakall, R., \& Smouse, P. E. (2006). GENALEX 6. Genetic analysis in Excel. Population genetic software for teaching and Research. Molecular Ecology Notes, $288-295$. http://dx.doi.org/10.1111/j.1471-8286.2005.01155.x

Perrier, X., \& Jacquemound-Collet, J. P. (2006). DARwin software. Retrieved from http://darwin.cirad.fr/darwin

Skerman, P. J., \& Riveros, F. (1990). Tropical Grasses (pp. 75-12). FAO, Rome.

Staal, S. J., Kruska, R., Balteweck, J., Kenyanjui, M., Wokobi, A., Njubi, D., ... Thorpe, W. (1999). Combined household and GIS analysis of smallholder production systems. An application to intensifying smallholder dairy systems approaches for Agricultural Development (SAAD-III) held in Lima, Peru, November 8-10, 1999. National Agrarian University, La Molina, Lima, Peru.

Strezov, V., Evans, T. J., \& Hayman, C. (2008). Thermal conversion of elephant grass (Pennisetum purpureum Schum) to bio-gas, bio-oil and charcoal. Bioresource Technology, 99, 8394-8399. http://dx.doi.org/10.1016/j.biortech.2008.02.039

Van de Wouw, M., Hanson, J., \& Luethi, S. (1999). Morphological and agronomic characterisation of 9 accessions of Napier grass. Tropical Grasslands, 33,150-158.

Wanjala, B. W., Obonyo, M., Wachira, F. N., Muchugi, A., Mulaa, M., Harvey. J., ... Hanson, J. (2013). Genetic diversity in Napier grass (Pennisetum purpureum) cultivars: implications for breeding and conservation. AoB PLANTS, 5, plt022. http://dx.doi.org/10.1093/ aobpla/plt022

Weising, K., Winter, P., Huttel, B., \& Kahl, G. (1998). Microsatellite markers for molecular breeding. Journal of Crop Production, 1(1), 113-143. http://dx.doi.org/10.1300/J144v01n01_06

Xie, X. M., Zhou, F., Zhang, X. Q., \& Zhang, J. M. (2009). Genetic variability and relationships between MT-1 elephant grass and closely related cultivars assessed by SRAP markers. Journal of Genetics, 88, 281-290. http://dx.doi.org/10.1007/s12041-009-0041-y 


\section{Copyrights}

Copyright for this article is retained by the author(s), with first publication rights granted to the journal.

This is an open-access article distributed under the terms and conditions of the Creative Commons Attribution license (http://creativecommons.org/licenses/by/3.0/). 